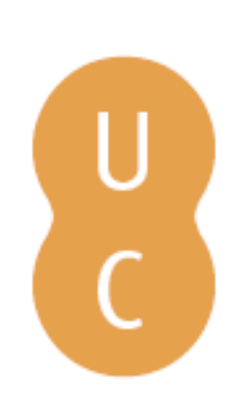

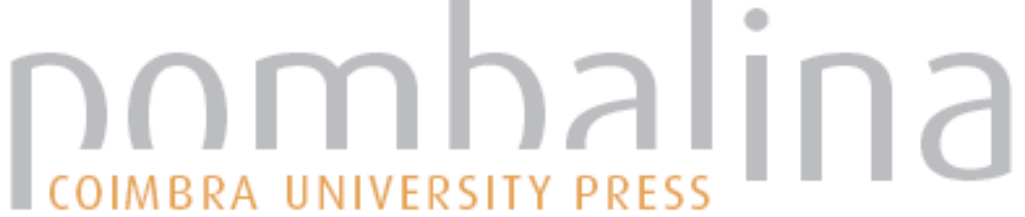

\section{Las monedas viajeras}
Autor(es):
Chaves Tristán, Francisca
Publicado por: Imprensa da Universidade de Coimbra
URL persistente:
URI:http://hdl.handle.net/10316.2/38348
DOI:
DOI:http://dx.doi.org/10.14195/978-989-26-0438-1_8

Accessed : $\quad$ 26-Apr-2023 11:20:59

A navegação consulta e descarregamento dos títulos inseridos nas Bibliotecas Digitais UC Digitalis, UC Pombalina e UC Impactum, pressupõem a aceitação plena e sem reservas dos Termos e Condições de Uso destas Bibliotecas Digitais, disponíveis em https://digitalis.uc.pt/pt-pt/termos.

Conforme exposto nos referidos Termos e Condições de Uso, o descarregamento de títulos de acesso restrito requer uma licença válida de autorização devendo o utilizador aceder ao(s) documento(s) a partir de um endereço de IP da instituição detentora da supramencionada licença.

Ao utilizador é apenas permitido o descarregamento para uso pessoal, pelo que o emprego do(s) título(s) descarregado(s) para outro fim, designadamente comercial, carece de autorização do respetivo autor ou editor da obra.

Na medida em que todas as obras da UC Digitalis se encontram protegidas pelo Código do Direito de Autor e Direitos Conexos e demais legislação aplicável, toda a cópia, parcial ou total, deste documento, nos casos em que é legalmente admitida, deverá conter ou fazer-se acompanhar por este aviso.

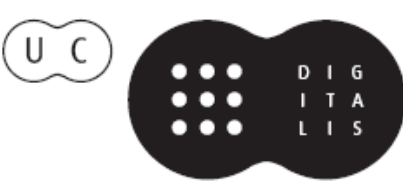


Francisco de Oliveira

Pascal Thiercy

Raquel Vilaça

Coordenação

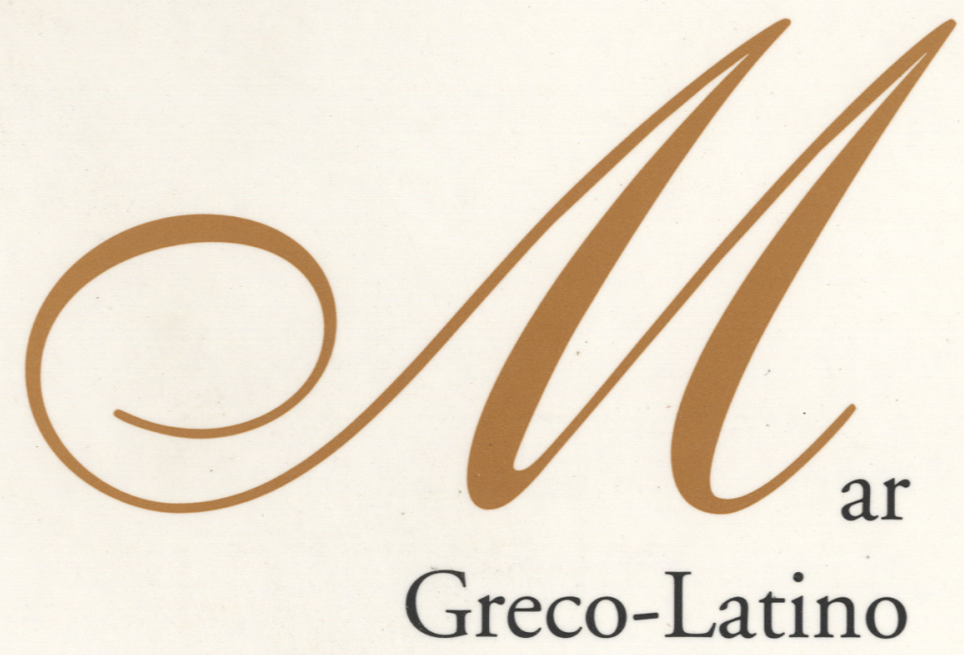

- colmbra 2006 


\title{
LAS MONEDAS VIAJERAS
}

\author{
Francisca Chaves Tristán \\ Universidad de Sevilla(*)
}

Durante mucho tiempo el estudio de las monedas que se produjeron en la antigüedad se centró en las piezas en sí mismas, sus tipos, las leyendas y el significado de éstas, los emisores y sus problemas, etc. Algunos autores repararon ya en el siglo XIX en el significado que pudiera tener seguir el desplazamiento de las monedas desde el lugar donde se habían producido hacia otros puntos más o menos distantes. Así se lee en la obra de D. Antonio Delgado, en artículos de su pluma y de sus colaboradores como D. Francisco Mateos $\mathrm{Gago}^{(1)}$, que el hallazgo frecuente de determinadas monedas en una zona hace suponer que la ceca productora se ubica en ella.

Ha sido sin embargo la investigación del siglo XX, cobrando gran impulso a partir del último tercio, cuando los estudiosos, siguiendo una metodología específica, se han planteado el problema del desplazamiento de las piezas monetales. Trabajos como el paradigmático de R. Reece ${ }^{(2)} y$, en nuestra Península, Congresos y reuniones al estilo del Simposium Numismático de

\footnotetext{
(*) Este trabajo se ha realizado dentro del Proyecto de Investigación financiado por a Junta de Andalucía y el Ministerio de Ciencia y Tecnología "Antecedentes y desarrollo económico de la Romanización en Andalucía occidental", dentro del grupo de Investigación "De la Turdetania a la Bética".

(1) A. Delgado, Nuevo Método de clasificación de la Medallas Autónomas de España, tomo II, Sevilla 1871, artículo de F. Mateos Gago sobre Lascuta, p. 163-164.

(2) R. REECE, "Roman coinage in Britain and the Western Empire", Britannia 4, 1973, pp. $227-271$.
} 
Barcelona $^{(3)}$ celebrado en 1978 o excelentes estudios como la circulación monetaria de Conimbriga ${ }^{(4)}$ o de Baelo Claudia $^{(5)}$, por citar solo algunos ejemplos, han abierto fértiles vías de investigación con una repuesta importante y numerosa bibliografía.

Las posibilidades de información de este tipo de estudios son amplias y a su vez complejas porque no existen patrones standard que puedan aplicarse infaliblemente a todas las épocas y a todos los conjuntos monetarios. En efecto no sólo hay que considerar la casuística político-social de cada momento sino la entidad de las monedas de manera que las piezas de oro, plata o bronce podrán seguir movimientos diferentes en una misma zona y época.

No es nuestra intención plantear aquí las bases de los estudios acerca de la circulación monetaria en la Antigüedad sino esbozar una reflexión ilustrándola con una serie de ejemplos, sobre las causas más frecuentes que obligan a las monedas a desplazarse, esto es, a viajar desde la ceca donde se han emitido hasta lugares a veces remotos y alejados. Este movimiento exógeno cobra especial interés como reflejo de una causa específica -política, económica, social- que impulsa a unos determinados agentes a portar las monedas fuera de su ámbito natural de circulación. De hecho, en buena parte del mundo antiguo las monedas perdían su valor para circular fuera del territorio para el que se habían producido y así, las ciudades griegas, que además utilizaban muy distintos patrones monetales, se veían obligadas a cambiar las piezas extranjeras por moneda local como se hace en la actualidad en tantos países. Tal actividad estaba perfectamente regulada y los textos epigráficos conservados dan clara noticia de ello ${ }^{(6)}$.

\footnotetext{
(3) Barcelona, 1979, 2 vols.

(4) I. Pereira, J. P. Bost, J. Hiernard, Fouilles de Conimbriga III. Les Monnaies, Paris 1974.

(5) J. P. Bost, F. Chaves, G. Depeyrot, J. Hiernard, J-C. Richard, Baelo IV. Les Monnaies, Madrid 1987.

(6) Por ejemplo, la ley monetaria de Olbia de mediados del siglo IV a. C., se refiere a algunas condiciones de dicho cambio: M. Crawford, La Moneta in Grecia e a Roma, Roma 1982, p.31. A partir del inicio del Imperio en Roma, los dominios de tan amplio territorio verían la circulación
} 
Sin embargo contemplar la moneda antigua con los ojos actuales, considerando las piezas entonces circulantes como el "dinero-moneda-billete" de hoy, induce a graves errores. Hemos de tener en cuenta que la moneda en sí representaba un valor, en especial la de oro, plata e incluso la de bronce, por su mero contenido metálico y esta razón hacía que se la aceptase en la vida cotidiana a pesar de que, en teoría, quedara fuera de su propia área de circulación lo que en el caso de la moneda actual no es lógico, salvo cuando la moneda local está depreciada y se recibe fraudulentamente la foránea de mayor valor con el fin de especular.

Es por tanto factible seguir el desplazamiento de las monedas antiguas, que viajaban por muy diversas razones como veremos enseguida, teniendo no obstante en cuenta que, una vez salidas del área donde debían circular, se movían con mayor rapidez porque quienes las recibían trataban de desprenderse de ellas antes que hacerlo de las emisiones locales merecedoras de más confianza. Había por tanto una tendencia endógena, inherente a las propias monedas, que podía ser alterada por causas diversas, varias de las cuales expondremos más adelante. No obstante dicha tendencia nos permite aventurar localizaciones de cecas cuyo emplazamiento es desconocido o dudoso siempre que esos datos no se contradigan con otros epigráficos o arqueológicos sino que los completen. Ya adelantamos cómo la reiterada presencia de hallazgos monetales en una zona concreta fue aprovechada por los autores del XIX y el sistema sigue aplicándose en la actualidad pudiéndose citar una serie de ejemplos como es el caso de las ibéricas ikalesken y kelin ${ }^{(7)}$. La localización de ambas, muy discutida, parece probarse gracias a los hallazgos monetales, combinando estos datos con otros de

\footnotetext{
de una moneda única, la estatal romana, con algunas excepciones en Oriente. Por ello los ejemplos que traeremos a colación líneas abajo se centran en la época anterior, cuando diversos estados y/o ciudades emitían simultáneamente moneda propia.

(7) P. P.; RIPOLlés, "Ikalesken, notas sobre su localización", X CIN (Albacete 1998), Madrid, 2002, pp. 187-188: se la sitúa entre los ríos Júcar y Cabriel, muy a distancia de otras propuestas realizadas; ibid. "La ceca de Celin. Su posible localización en relación con los hallazgos monetales", Saguntum 14, 1979.
} 
fuentes diversas. No obstante estas informaciones deben manejarse con cuidado porque a veces proceden tales noticias de buscadores clandestinos y pueden reflejar una realidad parcial ya que es posible que se hayan obtenido a partir de un tesorillo desmembrado y no de hallazgos esporádicos lo que alteraría su interpretación.

Mencionando los tesoros es preciso considerar la importancia que tienen las ocultaciones de monedas que no fueron recuperadas por sus dueños, para interpretar los desplazamientos de las piezas contenidas en ellos. En efecto, la tendencia a la tesaurización de metales, en especial nobles, es permanente durante toda la Antigüedad con etapas más acentuadas en momentos de peligro o de alteraciones de las especies monetarias recién emitidas. Lógicamente esto produce una retirada de las piezas circulantes, inmovilizándose al ser ocultadas, lo que les impide "viajar" cambiando de manos, al menos durante un tiempo. Sin embargo, como veremos enseguida, el estudio de los tesoros que nunca pudieron recuperarse y por fortuna se han hallado hoy, nos ilustra ampliamente de los "viajes" previos que las monedas guardadas habían realizado.

Pero es momento de preguntarse cuáles fueron los caminos más fáciles de frecuentar por medio de los agentes portadores de la moneda...o de la moneda en sí puesto que también grandes cantidades de piezas se enviaban para efectuar pagos a distancia como se expondrá más abajo con algún ejemplo. Está sobradamente probado que en el mundo antiguo el viaje y el transporte por mar o por vía fluvial ${ }^{(8)}$ era mucho más barato, rápido e incluso a veces menos peligroso, que el transporte por tierra. La travesía del Mediterráneo resultó el medio más idóneo para que monedas de toda clase

\footnotetext{
(8) G. CHIC, Historia económica de la Bética en época de Augusto, Sevilla 1997, pp.55, 61 ss.; ibid. "El Baetis-Guadalquivir, puerta de Hispania", Actas del I Ciclo de Estudios sobre Sanlúcar, vol. I, Sanlúcar de Barrameda, 2004, pp. 41-66.
} 
cruzasen de orilla a orilla y, en tristes ocasiones, se hundiesen en sus profundidades para siempre. No son raros los hallazgos monetales en pecios como el de Cabrera (Mallorca) ${ }^{(9)}$, donde se hallaron, dentro de un ánfora,

967 monedas del siglo III. Entre otros podemos recordar el hallazgo de Portimao ${ }^{(10)}$ que nos muestra la presencia de las monedas, también romanas del siglo III, pero esta vez surcando aguas atlánticas.

Las costas resultaban por tanto los lugares más frecuentes de recepción de monedas que viajaban por motivos diversos arribando a los más concurridos puertos. Así, en la Península Ibérica, puertos como Gadir, Malaca o Emporion $^{(11)}$ conocen la llegada de monedas de muy diversas procedencias. Pero es interesante reflexionar acerca de quiénes pudieron ser los más frecuentes portadores de las monedas en sus viajes atravesando el Mare Nostrum y cuáles fueron las razones que les impulsaron.

Quizá la causa más llamativa del movimiento de las monedas en el mundo antiguo sea la guerra. Recordemos que uno de los motivos -aunque no el único- que se han esgrimido para justificar el inicio de las amonedaciones en ciertos estados como por ejemplo el cartaginés, ha sido la necesidad de financiar sus campañas bélicas. En este sentido el mismo Crawford intentó evaluar el volumen de la producción monetaria de la República Romana según el número de legiones que debía mantener cada anualidad aunque

\footnotetext{
(9) J. P. BosT; M. CAMPO et alii, L'épave Cabrera III (Majorque): échanges commerciaux et circuits monétaires au milieu du IIIè siècle après Jésus Christ, Bordeaux, 1992.

${ }^{(10)}$ F. TEICHNER, "Un hallazgo de monedas en el "mare externum", Homenaje a Hermanfrid Schubart, BAEAA n $\mathrm{n}^{\circ} 35,1995$, pp. 281-287.

(11) Malaca: B. MORA: "La circulación monetaria en los territorios malacitanos durante la Antigüedad" en F. Wulff et alii eds. Comercio y comerciantes en la Historia Antigua de Málaga (siglo VIII a. C. -año 711 d. C.), Málaga 2001, pp. 419-455; G. CHIC, "Comercio y comerciantes en la Málaga republicana y alto-imperial", ibid, pp. 351-384; Emporion: M. CAMPO, "En torno a dos conjuntos de monedas de bronce procedentes de Ampurias" Anejos de AEspA, XX 1999, pp. 175-184; ibid. "Sobre dos depósitos de denarios romano-republicanos procedentes de Emporion", X CNN, 2002, pp. 327-333; ibid. "Emissió e circulació monetàries al nord-est de la Hispania Citerior al final de la República", La moneda al final de la República entre la tradició $i$ la innovació, IX Curs d'Història Monetària d'Hispània, Barcelona 2005, pp. 76-93.
} 
estos cálculos no han sido aceptados unánimemente por varias razones ${ }^{(12)}$. Pero de lo que no cabe duda es que la guerra no sólo requeriría inversión de dinero, que en el caso de países más o menos monetizados se materializó en gran parte al menos en moneda, sino que hizo que tales piezas se moviesen y viajasen incluso a través de grandes distancias, bien enviadas oficialmente, bien llevándolas consigo los componentes del ejército de modo privado.

Tratar este amplio y sugerente tema en profundidad rebasa con mucho los límites de espacio de los que aquí se dispone pero nos permite esbozar algunos puntos que reflejan la importancia que los factores bélicos tuvieron en el desplazamiento de los especímenes monetarios. El primer problema que se plantea es conocer si los soldados y/o mercenarios cobraban todo su salario in situ o al regreso de las campañas ${ }^{(13)}$. Está claro que no hay una sola respuesta capaz de abarcar el funcionamiento de todos los ejércitos de cada país del mundo antiguo, pero sí sabemos que los movimientos de tropas arrastraron consigo un desplazamiento inusual de monedas y llegaron a requerir a veces una producción extraordinaria de emisiones que, en no pocos casos, se realizarían en talleres de campaña ${ }^{(14)}$, en especial si los enfrentamientos tenían lugar en territorios alejados a la ubicación de la ceca oficial. Es evidente que estas monedas nacían ya expresamente creadas para

\footnotetext{
(12) M. CRAWFORD, Roman Republican Coinage, Cambridge 1974; contra B. W. FrIER, "Roman Coinage and army pay: techniques for evaluating statistics", Quad.Tic. NAC X, 1981, pp. 285-295; E. LO CASCIO, "Spessa militare, spessa dello stato e volume delle emissioni", AIIN 1982, pp. 75-97, en especial p. 88 y nota 53 con la bibliografía sobre las matizaciones hechas a Crawford.

(13) Sobre los mercenarios, con abundante bibliografía, véase F. QuESADA, "Vías de contacto entre la Magna Grecia e Iberia: la cuestión del mercenariado", Arqueología de Sicilia, Magna Grecia y la Peninsula Ibérica, Córdoba 1994, pp. 141-246; id. "Soldada, moneda, tropas ciudadanas y mercenarios profesionales en el antiguo Mediterráneo: el caso de Grecia", en Moneda i exèrcits, III Curs d'Història monetària d'Hispània, Barcelona 1999, pp. 9-37; T. ÑACO, A. PRIETO, "Moneda e Historia en la Hispania republicana: ¿economía, política, fiscalidad?", StH 17, 1999, en especial pp. 211-212.

(14) F. Chaves Tristán: "El lugar de las cecas en la Hispania Romana", en Convegno I Luogbi della Moneta. Le sedi delle zecche dall' Antichità all'età Moderna, Milano 2001, pp.199-218.
} 
viajar con las tropas, acantonadas lejos de sus puntos de origen, con frecuencia con las aguas del mar por el medio.

Las razones más habituales para ello eran debidas al retraso en la llegada de un suministro monetal adecuado o a la necesidad de su uso inmediato, como ocurrió por ejemplo durante la guerra sertoriana en que Annio, general al mando de las tropas senatoriales contra Sertorio, fue autorizado para emitir moneda en Hispania ${ }^{(15)}$, También se recurriría a ello cuando uno de los grupos beligerantes actuaba por sí mismo sin contar con el numerario de la ceca oficial. Es el caso de buena parte de la amonedación cesariana durante las guerras civiles del siglo I a.C. en Roma $^{(16)}$ la cual, según Crawford ${ }^{(17)}$, era ilegal ante los ojos del Senado.

Era normal que las monedas viajasen con los ejércitos porque, independientemente del arribo de las soldadas, sus componentes debían hacer frente a pequeños gastos más o menos cotidianos, que les obligaban a manejar moneda fraccionaria. Es seguramente por esta razón por la que en campamentos romanos como Numancia ${ }^{(18)}$, Cáceres el Viejo ${ }^{19}$ o Choes de Alpompé $^{20}$ se encuentra moneda local hispana de bronce. También los periodos en que las tropas romanas invernaban eran sin duda propicios para que los soldados cambiasen parte del dinero que podían necesitar al usarlo

\footnotetext{
(15) C. MARCos, "La moneda en tiempos de guerra: el conflicto de Sertorio", Moneda i exèrcits, III Curs d'Història Monetària d'Hispània, Barcelona 1999, p. 87 ss.

(16) Sobre el importante papel desempeñado por las monedas en este conflicto, F. CHAVES TRISTÁN, "Guerra y moneda en la Hispania del Bellum civile", en E. Melchor, J. Mellado, J. F. Rodríguez Neila, Julio César y Córdoba: Tiempo y Espacio en la campaña de Munda (49 - 45 a.C.), Córdoba 2005, pp. 207-245.

(17) RRC p. 604.

(18) A. JimenO, A. Ma . MARTIN, "Estratigrafía y Numismática: Numancia y los campamentos", M ${ }^{a}$. P. García-Bellido, M. S. Centeno eds. La moneda hispánica, ciudad y territorio, I EPNA Anejos AEspA XIV, 1994, pp. 179-190.

${ }^{(19)}$ H. J. Hildebrand, "Die Römerlager von Numantia. Datierung anhand der Münzfunde", $M M 20$ 1979, pp. 238-271.

(20) J. Ruivo, "Moedas do acampamento romano republicano dos Chôes de Alpompé (Santarem)", R. M. S. Centeno, M ${ }^{a}$. P. García-Bellido, eds., Rutas ciudades y moneda en Hispania, II EPNA, Anejos AEspA, XX, 1999, pp. 101-110; C. FABIÃO, "Arqueología militar romana en Lusitania: textos e evidências materiais", C. Pérez González, E. Illarregui eds, Arqueología militar romana en Europa, Segovia, 2005, p. 58-59.
} 
para gastos menores en moneda local de bronce, moneda que viajaría con ellos a lo largo de sus campañas. Los casos son numerosos, baste con 146 recordar el tantas veces mencionado de Azaila ${ }^{(21)}$ donde un tesorillo que se supone "bolsa de soldado" contiene variadas monedas que ilustran el itinerario de su dueño.

De todas formas, aunque se ha repetido en numerosa ocasiones, la "bolsa de soldado" no es siempre fácil de delimitar, incluso habría que distinguir matices muy importantes entre el numerario que portaba un mercenario ${ }^{(22)}$, un soldado o legionario, y el que podían llevar mandos superiores de la tropa ${ }^{(23)}$. Con solo algunos ejemplos advertiremos que la casuística varía bastante de una zona y de una época a otra y que cualquier generalización resulta peligrosa.

Fijamos ahora nuestra atención en el Mediterráneo, cruzado en frecuentes ocasiones por ejércitos pertenecientes a pueblos que utilizaban moneda. Si leemos a Jenofonte (Anab.VI, 4, 8) éste nos habla del deseo de regresar con dinero que mantenían los 10.000 soldados griegos desplazados a Oriente, pero en otro paso indica que "algunos mercenarios habían guardado la paga" (Anab. V, 6, 15), como observa F. Quesada ${ }^{(24)}$, lo cual da a entender que otros ya se la habían gastado. Vemos por tanto que las monedas persas, a pesar de que se considera que su buen peso y excelente calidad de metal precioso las hacían codiciadas sus contemporáneos, no siempre viajaban de regreso con los miembros de los ejércitos y, de hecho, no son tan habituales en los tesoros de Grecia como cabría esperar ${ }^{(25)}$.

\footnotetext{
(21) J. Romagosa, "Azaila: dos tesoros, dos mensajes", Acta Numismática I, 1971.

(22) Acerca de las pagas u otras compensaciones a los mercenarios, con abundante bibliografía al respecto, véase F. QUESADA, cit. en nota 13, 1994, pp. 214-224; ibid. 1999, pp. $24-29$.

${ }^{(23)}$ Las diferencias en las soldadas se mantenían también cuando se hacían repartos extraordinarios o donativa. Así Apiano (BCiv. 2,102) menciona que en un reparto de César a sus soldados, los centuriones reciben el doble de esa cantidad y cada tribuno de infantería y prefecto de caballería el cuádruple.

(24) Véase F. QueSADA, op. cit. nota 13, 1994, pp. 220, 222.

(25) De todos modos sí se encuentran tesoros de moneda persa, algunos correspondientes al momento de la invasión. Conocido es por ejemplo el de dáricos hallado en el canal de Jerjes,
} 
No las acciones directas de guerra pero sí los estragos de la misma han dejado una hilera de tesoros en el norte de África, en las costas egipcias, debidos a los griegos jonios que huían de la invasión persa de la actual Turquía. De hecho, las monedas de Mileto, Egina, Efeso y tantas otras ciudades de Jonia fueron compañeras de viaje de los atemorizados griegos que navegaban hacia occidente buscando refugio quienes, recalando en el norte de África, perdieron a veces para su desgracia la vida y el tesoro que portaban ${ }^{(26)}$. De forma similar, las precipitadas huídas de ricos personajes romanos a causa de proscripciones y/o persecuciones del partido opositor, dieron origen a que trasladasen con ellos grandes cantidades de numerario, viéndose con frecuencia obligados a atravesar el Mediterráneo. Los sangrientos enfrentamientos entre marianos y silanos fueron uno de esos momentos. Recordemos, por citar alguno con relación a Hispania, cómo L. Licinio Craso, huyendo de Roma, se refugió en la finca malacitana de su amigo C. Vibius Paciaecus y, tras saquear Malaca, navegó por el Mediterráneo hasta el norte de África buscando a sus amigos senatoriales (Plut., Craso, 4-6). Las guerras civiles en Roma fueron asimismo objeto de un gran movimiento de la masa monetaria perteneciente a capitales privados debido a las ayudas y préstamos que recibieron cada uno de los contrincantes por sus partidarios, en especial el bando pompeyano, aunque no siempre era preciso el desplazamiento físico de los ejemplares monetarios ${ }^{(27)}$.

Hay ocasiones en que el camino de vuelta de las monedas ya cobradas por los mercenarios es evidente. A finales del siglo IV a. C., un buen número de cretenses se enroló para intervenir en las contiendas que por entonces estaban teniendo lugar en el norte de África, en la zona donde se situaba

cerca de la península balcánica, en el monte Athos: C. M. KrAAY, Archaic and classical Greek Coins, London 1976, p. xxv.

(26) M. Price, N. Waggoner, Archaic Greek Silver Coinage: the Asyut Hoard, Londres, 1975. C. M. KraAY, op. cit. nota 25, p. 51.

(27) Así en el caso del préstamo de Cicerón a Pompeyo: L. Amela, "Cicerón y los cistóforos (Cic. Att. 2, 6, 2; 2, 16, 14 y 11, 1, 2)", Faventia 26, 2, 2004, pp. 91-98; J. ANDrEAu, Banques et affaires dans le monde Roman, (IVè siècle av. J. C. IIIè ap. J. C.), Paris, 2001. 
Cirene, ciudad emisora de potentes series de plata. Los salarios cobrados cruzaron el mar en sus bolsas hasta llegar a Creta y allí se aprovecharon las piezas norte-africanas siendo reacuñadas esas monedas cirenaicas superponiéndoles cuños de las ciudades-cecas de la isla que las convertían en moneda cretense ya que un cierto número de ellas ha llegado a nuestros días. ${ }^{(28)}$

Pero considerar siempre al mercenario como un agente activo en el movimiento de las monedas y en su travesía mediterránea, no es tan claro. Un caso que podría sorprender conocida la abundancia de moneda que acuñan tanto griegos como cartagineses en el sur de Italia y Sicilia, es el de los mercenarios hispanos de los que sabemos por las Fuentes que eran contratados por ambos bandos en los siglos V-III a. C. Se ha especulado con estos contingentes considerándolos incluso agentes de helenización ${ }^{(29)}$, sin embargo ni siquiera tenemos testimonios de que trajesen consigo la moneda cobrada ante la ausencia de hallazgos con rarísimas excepciones. Este tema ha sido tratado por F. Quesada ${ }^{(30)}$ quién aduce una serie de razones que pudieran explicar esa ausencia. Sin embargo el tema no está definitivamente aclarado porque otros mercenarios, procedentes de diversas zonas de Europa sí parece que regresaron con el contenido de sus pagas como muestran los tesoros de moneda coetánea hallados ${ }^{(31)}$.

Para el movimiento de la moneda cartaginesa, portada por los soldados, surcando el Mediterráneo, podemos considerar una serie de testimonios que a veces resultan divergentes. La razón es que las circunstancias no son siempre las mismas y se intercalan elementos modificadores según el momento

\footnotetext{
(28) S. GARAFFo, "Riconiazioni e politica monetaria a Creta: le emisioni argentee del V al I secolo AC", Antichitá cretesi, Studi in Onore di Doro Levi 2, Catania, 1974, pp. 59-74; G. Le Rider, "Contramarques et surfrappes dans l'Antiquité grecque", Numismatique Antique. Problèmes et Méthodes, 1975 , pp. 46-47.

${ }^{(29)}$ Así desde A. García y Bellido, citado este autor y discusión sobre el tema en F. QUESADA, op. cit. en nota 13, p. 192 ss.

(30) Op. cit. en nota 13, p. 216 ss.

(31) Y. GARLAn, Guerre et économie en Grèce Ancienne, Paris, 1988, p. 71 (obra no vista, cit. por F QUESADA, op. cit. en nota 13, p. 216-217).
} 
político y las condiciones económicas. Ya hemos mencionado cómo los cartagineses se vieron impelidos a emitir moneda al contacto con los griegos en Sicilia y ante la necesidad de facilitar con un numerario propio sus ansias imperialistas en esta zona del Mediterráneo. Por estas razones, las monedas emitidas en Cartago debían atravesar el mar que les separa de Sicilia pero, para mayor facilidad, el Estado cartaginés también emitió moneda propia en las zonas conflictivas, evitando - o mejor, aminorando- así un continuo y obligado viaje de las monedas del norte de África a la zona siciliana. Por las mismas razones acuñaron moneda primero en Cerdeña y, más adelante, en la misma Península Ibérica.

Tanto los largos años de enfrentamientos como el afán de Cartago de explotar los recursos de su incipiente imperio, posibilitaron que las monedas acuñadas en el ámbito cartaginés africano, siciliano y sardo, se desplazasen a través del Mediterráneo ${ }^{(32)}$. Con referencia a la Península Ibérica nos detendremos a continuación en tres casos de interés.

En época reciente, y a través de informaciones obtenidas con suma paciencia y tacto, procedentes en parte de colecciones particulares, se ha conseguido detectar una serie de piezas cartaginesas emitidas antes de la II Guerra Púnica(33) y encontradas eu suelo andaluz aunque hasta ahora habían permanecido ignoradas ${ }^{(34)}$. Estos hallazgos han planteado la cuestión

\footnotetext{
(32) Amplísima bibliografía para lo que puede ser útil muy L. I. MANFREDI, "Produzione e circolazione delle monete puniche nel sud dell'Italia e nelle isole del Mediterráneo occidentale (Sicilia e Sardegna)", en M M. P. García-Bellido, L. Callegarin eds, Los cartagineses y la monetización del Mediterráneo occidental, Anejos AEspA XXII, pp. 11-22; L. CALLEGARIN, F. Z. EL Harrif, "Ateliers et échanges monétaires dans le Circuits du Detroit", ibid., pp. 23-42.

${ }^{(33)}$ R. PLIEGO, "Sobre el reclutamiento de mercenarios turdetanos: el campamento cartaginés de El Gandul (Alcalá de Guadaira, Sevilla)", Habis 34, 2003, pp. 39-56; Ibid. "Un campamento cartaginés del siglo IV a. C. en El Gandul (Alcalá de Guadaira Sevilla)”, RSF XXXI, 1, 2003, pp. 31-67; Ibid. "Un nuevo conjunto monetal cartaginés procedente de El Gandul (Alcalá de Guadaira, Sevilla)", XIII CIN, Madrid, 2005, pp. 531-533; E. FERRER, "Fenicios y cartagineses en el Tartessos postcolonial", en El nacimiento de la ciudad. La Carmona Protobistórica, V Congreso de Historia de Carmona, Carmona 2005 (en prensa, cortesía del autor)

(34) En un trabajo sobre un tema similar publicado hace años no se conocían aún, o no se había tenido acceso, a las monedas últimamente estudiadas: F. CHAVES TRISTÁN, "Los hallazgos numismáticos y el desarrollo de la II ${ }^{a}$ Guerra Púnica en el Sur de la Península Ibérica", Latomus XLIX, 3, 1990, pp. 613-622. Años después C. ALFARO publicó sendos artículos en donde se aludía
} 
del paso, a través del Mediterráneo, de la moneda acuñada en Cartago o en sus zonas de dominio hacia la zona sur de Iberia $^{(35)}$ en época anterior al primer enfrentamiento directo entre romanos y cartagineses, es decir, a la primera Guerra Púnica.

Por el momento los testimonios publicados más numerosos y evidentes se refieren a un yacimiento determinado, El Gandul (Alcalá de Guadaira, Sevilla) y a la zona de Fuentes de Andalucía (Sevilla) ${ }^{(36)}$, aunque se está en espera de obtener otros datos que amplíen la información geográfica. De todos modos, las propuestas actuales acerca del uso de este numerario para reclutar mercenarios, se centran básicamente en monedas de bronce lo que plantea algunos problemas. Es cierto que las series iniciales, más tardías, de la primera ceca fenicia sur hispana que emite moneda, Gadir, se limitarían a piezas de bronce, pero también lo es, como más adelante veremos, que la finalidad de éstas nada tiene que ver con movimientos bélicos.

La presencia de las mencionadas piezas de bronce cartaginés en este estratégico punto sur-peninsular podría relacionarse con un centro de reclutamiento de mercenarios indígenas ${ }^{(37)}$, pero no con las soldadas que ellos fueran a recibir. No tenemos ninguna constancia de que los pueblos del interior utilizaran la moneda en ese momento y los pequeños bronces no creemos que hubieran resultado un metal aceptable como pago. En todo caso, y aparte de la esperanza de un sabroso botín a obtener en un territorio de ultramar - Sicilia - que por tradición se suponía rico, sólo los metales

a algunas piezas anteriores a la segunda Guerra Púnica: "La producción y circulación monetaria en el sudeste peninsular", en $\mathrm{M}^{\mathrm{a}}$. P. García-Bellido, L. Callegarin eds, Los cartagineses y la monetización del Mediterráneo occidental, Anejos AEspA XXII, pp.103-104 y "Consideraciones sobre la moneda púnica foránea y su entorno", BMAN 18, pp. 21-68.

${ }^{(35)}$ Se trata de un ambiente cercano al río Baetis que, debido a unas condiciones geomorfológicas diferentes a las de hoy, estaba bien relacionado con la costa.

(36) Véase nota 33

(37) Muy interesante es la idea que apunta F. QUESADA - op. cit. nota 13, p. 203-206 - sobre la distinción entre puertos de embarque y centros de reclutamiento, controlados éstos últimos con frecuencia por los mismos indígenas. Asimismo hay que reflexionar sobre la hipótesis de $\mathrm{E}$. FERRER -op. cit. en nota 33- acerca de un episodio bélico que justifique la posible presencia de elementos cartagineses en torno a Carmo. 
preciosos acuñados, susceptibles de ser fundidos a la vuelta, podían atraer la atención y/o codicia de los voluntarios dispuestos a enrolarse. Además, con respecto a Sicilia, sabemos por las Fuentes ${ }^{(38)}$ que los gobernantes griegos se vieron en ocasiones obligados a fundir los tesoros de algunos templos para conseguir metales nobles y acuñar moneda con que pagar a los mercenarios. Asimismo es interesante un pasaje de Livio (XXX, 21,3), aunque pertenece a un momento posterior, donde se dice que en 203 a.C, los cartagineses enviaron a Sagunto oficiales encargados de reclutar mercenarios con 250 libras de oro y 800 de plata ${ }^{(39)}$.

Sin embargo es evidente que la moneda de bronce debía cumplir una función interesante, complementaria a las de metales nobles, aunque en esta época inicial no la conocemos con precisión y seguramente se limitaba a círculos o a funciones concretas. Respecto al caso hispano arriba mencionado nos preguntamos si podía ser transportada por los reclutadores foráneos y utilizada para compensar algunos servicios que se nos escapan pero que habrían contribuido a que, poco a poco, su aprecio se extendiera hacia el interior al menos en ciertos ambientes. Sí es claro que durante la segunda guerra púnica la moneda de bronce llegó a desempeñar junto a las emisiones de plata un papel importante a juzgar por el gran volumen de las emisiones producidas. Incluso se puede hablar de una supuesta "bolsa de soldado", compuesta por piezas de bronce, que se halló en las excavaciones de la Torre de Doña Blanca (Puerto de Santa María, Cádiz), junto a la muralla defensiva ${ }^{(40)}$.

Pero veamos un segundo dato: en el puerto de Melilla, antigua Russadir, las labores de dragado de dicho puerto, en los años 1953 y 1981, exhumaron

\footnotetext{
(38) Véase F. QUESADA, cit. en nota 13, 1994, p. 207 y 1999, p. 27, donde se recogen algunas citas.

(39) Esto es, $81 \mathrm{Kgr}$. de oro que, suponiendo que se mantuviese un peso de 7'60 grs. La unidad, venían a ser 10.658 piezas de monedas, y $260 \mathrm{Kgr}$. de plata que equivalían a 36.112 shekel, conteniendo la unidad argéntea 7’20 grs., si seguimos la metrología propuesta por L. VILLARONGA, Las monedas hispano-cartaginesas, Barcelona, 1973, pp. 95-107.

${ }^{(40)}$ C. Alfaro, C. Marcos, "Tesorillo de moneda cartaginesa de La Torre de Doña Blanca (Puerto de Santa María, Cádiz)”, AEspA 67, 1994, pp. 229-244.
} 
un enorme cargamento de monedas emitidas en la ceca de Cartago que procedian de un barco que tuvo la mala fortuna de naufragar a finales del siglo III a.C. con - al parecer ${ }^{(41)}$ - miles de monedas entre las que había ejemplares de electron pero en especial una gran cantidad de piezas de bronce. Las monedas iban viajando en un barco que sin duda había salido de Cartago con monedas producidas en su ceca, y se dirigía creemos que a la Península Ibérica aunque no tenemos seguridad de ello, pero es la ruta más probable. En este caso parece razonable suponer que esas monedas se hubieran destinado a gastos relacionados con el ejército si bien no tienen necesariamente que ser las piezas de bronce la paga de los mercenarios sino un complemento de ésta que facilitase el cambio y los gastos menores.

Un tercer dato nos sume en un terreno contradictorio: las fuertes emisiones que los bárcidas realizaron en Hispania con la plata obtenida de sus minas ${ }^{(42)}$, emisiones que nadie duda sirvieron para financiar sus ejércitos durante la segunda Guerra Púnica, se quedan en Hispania y apenas se encuentran en Italia o en el norte de África a pesar de la presencia de los ejércitos que Aníbal desplazó de la Península Ibérica a Italia. Ciertamente hay un paso de Polibio (III, 35, 6) donde se menciona que Aníbal licenció antes de cruzar los Alpes a un buen número de soldados $^{43}$, pero también es evidente que en las Fuentes se menciona a otros muchos soldados procedentes de la Península Ibérica que participaron en batallas cruciales

\footnotetext{
(41) Noticias de las personas que conocieron este hallazgo hablan de enorme cantidad de piezas que en gran número desaparecieron en muchas manos. Un lote permaneció en el Ayuntamiento de Melilla, lote con poco electron y bastante bronce de tipos muy repetidos, que en la actualidad tenemos en estudio tras habérsenos encargado en su momento por el Ministerio de Cultura Español y catalogar el material en la propia Melilla. Otro conjunto de monedas fue a parar a una colección particular de Madrid y pudo ser publicado por C. Alfaro: "Lote de monedas cartaginesas procedentes del dragado del puerto de Melilla", Numisma 232, 1993, pp. 9-46. Durante este mismo Congreso hemos tenido con sorpresa noticia de que también M. Martín Bueno había recogido en su día el material melillense, algo totalmente ignorado por nosotros. Esperamos que pueda coordinarse la publicación adecuada.

(42) Una serie de análisis sobre estas piezas en G. SEJAS DEL PIÑal, "Consideraciones sobre la política monetaria bárquida a partir del análisis de sus monedas de plata", RSF XXI, 1, 1993, pp. 111-136.

${ }^{(4.3)}$ Cit. en nota 13, 1994, p. 220.
} 
como Metauro, Grandes Llanuras etc. (Livio, XXI, 11, 33; XXIV, 42, 6). Si las monedas emitidas en Hispania por los cartagineses no les acompañaron ¿se quedaron en la Península Ibérica ? ¿fueron fundidas al acabar la conțienda?

Esta serie de ejemplos, aparentemente contradictorios, se vuelven a repetir a lo largo del dominio romano del Mediterráneo afectando con frecuencia a nuestra Península Ibérica. Traemos a colación solo dos ejemplos relacionados con el movimiento de la moneda a causa de la guerra. Uno se refiere al tema, tantas veces repetido, de la ausencia en Italia de moneda de plata producida en Hispania, el célebre "denario ibérico", a pesar de las reiteradas menciones de las Fuentes que llegan a evaluar la cantidad de dinero que los generales victoriosos llevaron al Erario romano en sus triunfos ${ }^{(44)}$. Las explicaciones de los autores que han tratado el tema son diversas, desde la fundición en Roma de dichas monedas a la ausencia de emisiones de denarios ibéricos en ese momento inicial de la conquista. Prescindiendo de éstos, en esa masa, que las Fuentes citan con el equívoco nombre de argentum oscense, debía incluirse además de la moneda cartaginesa que aún quedase, la plata emporitana y las imitaciones de la misma que habían emitido los pueblos ibéricos así como las dracmas de la costa levantina, básicamente de Arse ${ }^{(45)}$. Nada de ello se encuentra en Italia. ¿Es posible que todo fuese fundido?

No deja tampoco de sorprender como las emisiones ya mencionadas que durante la guerra sertoriana sabemos que se permitió al cónsul Annio emitir en suelo hispano para hacer frente a las necesidades más perentorias de la guerra, sean poco frecuentes en la propia Península mientras que otras series

${ }^{(44)}$ E. GarCia RiaZA, "La financiación de los ejércitos en época romano-republicana", Moneda $i$ exércits, III Curs d'Història Monètaria d'Hispània, Barcelona, 1999, pp. 39-58; Id. "Especie, metal, moneda: consideraciones en torno a la cuantificación de las exacciones romanas en Hispania republicana", II EPNA, Anejos AEspA XX, 1999, pp. 39-46.

${ }^{(45)}$ Debe además tenerse en cuenta tanto las novedades como el alza cronológica de esta ceca que se refleja en el estudio reciente de P. P. RIPOLLÉS, M. M. Lloréns, Arse-Saguntum Historia monetaria de la ciudad y de su territorio, Valencia, 2002. 
sin duda producidas en la ceca de Roma, en circunstancias diferentes y por motivos diversos, parecen llegar con más facilidad ${ }^{(46)}$.

154 De todas formas es innegable que la moneda se movía con el ejército o, dicho de otra manera, el ejército necesitaba moneda para moverse, como las numerosas emisiones realizadas en campaña durante las guerras civiles (I y II triunviratos) de Roma lo demuestran ${ }^{(47)}$. De hecho en estos casos y también en muchos otros, hay series monetales que están concebidas expresamente para mantener a las tropas como por ejemplo a las legionarias de Antonio, tropas que están en continuo desplazamiento y que de una u otra forma acabarán arrastrando con ellas las monedas. Aparte de los salarios, de los cuales ya vimos que se discute si se recibían siempre en plena campaña o a la vuelta, es interesante contar con los premios o donativa que los generales repartían para tener satisfecha a la tropa ${ }^{(48)}$. Es asimismo bien sabido que hubo emisiones e incluso cecas cuya producción se destinó específica y directamente al abastecimiento del ejército y que algunos hallazgos se interpretan como "cajas militares". Así explica ciertos conjuntos de tesoros sicilianos $\mathrm{M}^{\mathrm{a}}$ A. Puglisi ${ }^{(49)}$ y también se ha dado la misma interpretación al contenido del supuesto barco de Melilla.

Pero todo esto no es razón suficiente para atribuir a los ejércitos un papel que a veces se ha querido considerar casi exclusivo en el transporte y movimiento de la moneda. Otros agentes estuvieron sin duda implicados en los desplazamientos de las piezas monetales y éstos nada tenían que ver ni

\footnotetext{
(46) F. CHAVES TRISTÁN: "Ritrovamenti monetali in Spagna: problemi di interpretazione", Congresso Internazionale a cura di G. Gorini: "Ritrovamenti monetali nel mondo antico: problemi e metodi", Padova 2002, pp. 203-221.

(47) F. CHAVES TRISTÁN, op. cit. en nota 16, pp. 207-245.

(48) Múltiples menciones en las Fuentes. J. MUÑIZ, El sistema fiscal en la Hispania romana. República y Alto Imperio, Zaragoza 1982.

${ }^{(49)} \mathrm{M}^{\mathrm{a}}$. A. Puglisi, "Distribuzioni e funzioni della moneta broncea in Sicilia dalla fini dal V sec. a. C. all'etá ellenistica", XIII CIN, Madrid 2005, p. 290 y nota 33. Supone cajas militares destinadas a proporcionar a los soldados y/o legionarios moneda de cambio. No obstante se habla aquí del siglo III a. C. en lugares donde la plata es moneda bien conocida, en la cual se cobra y circula con fluidez, por lo tanto no podemos extrapolar esto al interior de la Iberia del siglo IV a.C. si pensamos aplicarlo a El Gandul.
} 
con la guerra ni directamente con las necesidades ligadas a ella. Hay un fuerte volumen de piezas que viajaron en la bolsa de sus portadores sólo por motivos económicos diversos y en un número que cada vez parece mayor de lo que hasta ahora se había supuesto. Es preciso repetir lo que ya decíamos antes, no se puede generalizar pensando que el fenómeno sea igual en todas las zonas del Mediterráneo ni en todos los momentos de la Antigüedad, pero sí hay claros testimonios de este movimiento de numerario por mar y tierra en manos de comerciantes y en pos de mercados y tratos.

El hecho de que el crédito fuera prácticamente inexistente en el mundo antiguo produjo un fuerte movimiento de la plata romana, en especial el denario, durante varios siglos ${ }^{(50)}$. Pero también ciertos testimonios nos llevan a pensar que las monedas, al menos en ciertos ambientes, se movieron en este sentido con soltura mucho tiempo antes y lo hicieron desligadas de una finalidad militar. El tantas veces analizado plomo de Pech Maho(51) muestra un acuerdo comercial, fechado ya en el siglo VI a.C., en cuya realización interviene el intercambio de monedas. En definitiva se estaba tratando en él de comercio entre dos orillas -gala e hispana- del Mediterráneo. La misma línea es la que explica la puesta en marcha de las cecas de Massalia y Emporion. El célebre tesoro de Auriol ${ }^{(52)}$, donde recientemente Villaronga ha demostrado la presencia de moneda anepígrafa emporitana ${ }^{(53)}$, así como otros tesoros y hallazgos esporádicos de monedas emitidas en una zona y

\footnotetext{
(50) G. CHIC, "Marco Aurelio y Cómodo. El hundimiento de un sistema económico", en L. Hernández Guerra ed., La Hispania de los Antoninos (98-100), II Congreso Internacional de Historia Antigua, Valladolid 2004, pp. 568-571. Sobre este tema véase J. ANDREAU, Banques et affaires dans le monde Romain, (IVè siècle av. J. C. IIIè ap. J. C.), Paris, 2001; M. I. FINLEY, La economía en la Antigüedad, Madrid 1974.

${ }^{(51)}$ M. Lejeune, J. Poullloux, Y. Solier, "Etrusque et ionien Archaïques sur le plomb de Pech Maho (Aude)", Rev Arch. de Narbonnaise 21, 1988, pp. 19-59; M. P. GarCía-Bellido, "El plomo de PechMahó", Acta Numismática 20, 1990, pp. 15-18.

${ }^{(52)}$ A. E. FÜrTwangler, Monnaies grecques en Gaule. Le trésor d'Auriol et le monnayage de Massalia 525/520 - 460 a. C., Friburg, 1978.

(53) L. VillakONGA, "L'emissió emporitana and cap de be i revers de creu puntejada de la segona meitat del segle V a. C.", Acta Numismática 25, 1995, pp. 17- 34; ibid. "La troballa de l'Empordà", Acta Numismática 33, 2003, pp. 15-46.
} 
aparecidas en la otra desde finales del siglo VI a.C. al III a.C. ${ }^{(54)}$, no pueden explicarse convincentemente por ninguna necesidad bélica. Tanto hallazgos aislados como ocultaciones hablan de unas monedas que atraviesan con sus portadores el mar que separa ambas orillas -gala e hispana- para solventar unos intereses económicos que nada tienen que ver con la guerra.

Un problema interesante pero no sencillo, tratado en repetidas ocasiones desde puntos de vista diversos, es el de la plata romana, el denario, que se desplaza cruzando el Mediterráneo de Roma a Hispania. ¿Entraban las monedas básicamente con el ejército y volvían a Roma mediante el pago de impuestos? ${ }^{(55)}$ Esta es una de las varias teorías que se han apuntado, pero las idas y venidas del material monetario hay que analizarlas no sólo desde una perspectiva financiera/económica teórica, sino conjugando la composición de los hallazgos, los lugares de los mismos, los valores encontrados y su frecuencia y, por supuesto, las condiciones políticas, sociales y económicas de cada zona y momento. Como en este espacio no podemos entrar a fondo en el tema exponemos tan sólo algunos puntos a tener en cuenta.

A lo largo de la II Guerra Púnica y durante su desarrollo en la Península Ibérica es sabido que en Roma circulaban los didracmas que conocemos como cuadrigatos. En lo que respecta al denario, aunque no está cerrada la polémica sobre la fecha exacta de su creación, tanto si consideramos la

\footnotetext{
(54) M. Campo, "Las monedas de los tesoros de Pont de Molins, Tarragona y Rosas del Gabinet Numismàtic de Catalunya", Studi per Laura Breglia, Boll. Num. I, 4, 1987, pp. 139-160; ibid. "Circulación de monedas massaliotas en la Península Ibérica (siglos V-IV a. C.)", Mélanges offerts au docteur J.-B. Colbert de Beaulieu, Paris 1987, pp. 175-188; M. Campo, A. Sanmartí, "Nuevos datos para la cronología de la moneda fraccionaria de Emporion (Revisión del tesoro Neapolis 1926)", Huelva Arqueológica XIII, 2, 1994, pp. 151-172; P. P. RIPOLLÉS, "Las monedas del tesoro de Morella conservadas en la BN de París", Acta Numismática 15, 1985, pp. 47-64; ibid. "El tesoro de Rosas", Saguntum 27, 1994, pp. 137-131; L. VIll.aronga, "Imitacions gàl-lique de les dracmes de Rhode i Emporion", Acta Numismática 16, 1986, pp. 21-52; ibid. "Les rapports numismatiques entre Massalia et Emporion", Quad. Tic. NAC XX, 1991, pp.85-92; ibid. "Tipus massaliotes a les monedes fraccionàries trobades a Catalunya", Acta Numismática 24, 1994, pp. 31- 48; ibid.. "À propos del monedes massaliotes inédites trouvées en Catalogne", Cahiers Numismatiques 129, 1996, pp. 7- 10; ibid. "Les monedes à la croix trobades a la península Ibèrica", Acta Numismática 30, 2000, pp. 19-32; ibid, cit en nota 53.

(55) M. CRAWFORD, "The finantial organization of republican Spain", NC 1969, pp. 79-90; E. LO CASCIO, "Spesa militare, spesa dello stato e volume delle emisioni", AIIN 29, 1982, pp. 75-97.
} 
propuesta por Crawford de 211 a.C. ${ }^{(56)}$ como la más reciente tendencia de la bibliografía $^{(57)}$ que sitúa su creación en 218 a.C., nos encontramos que también los denarios existían prácticamente al inicio de la intervención directa de Roma en Iberia. Resulta por tanto esperable que esa plata romana estuviese presente en Hispania a través de las soldadas del ejército. Sin embargo muy pocos cuadrigatos han sobrevivido en circulación en nuestra Península y las series de denarios iniciales son asimismo muy escasas ${ }^{(58)}$ en las tesaurizaciones posteriores o en hallazgos aislados.

Naturalmente hay ciertas explicaciones pero que no nos resultan suficientemente satisfactorias. La más convincente es que, según Crawford ${ }^{(59)}$, los soldados romanos no cobraron en plata hasta el 150 a. C. Sin embargo es muy difícil admitir desde un punto de vista lógico, que los mandos superiores e incluso intermedios, en una confrontación donde el ejército enemigo manejaba profusamente la plata ${ }^{(60)}$, no requiriesen moneda de este metal. Las Fuentes nos refieren cómo en un principio Escipión solicitaba con urgencia el auxilio económico del Senado para mantener la guerra (Liv. XXIII, 48,4-5), auxilio que en esos momentos se pudo paliar por la intervención de las societates publicanorum y que, al parecer, más adelante los generales en

\footnotetext{
(56) M. CRAwFord, Roman Republican Coinage, Cambridge, 1974, p. 28 ss.

(57) R. M. Nicolal, La circolazione del denario republicano nella peninsola italica fino alla metà del II secolo a. C., Roma 2004, en la página web de la Università Roma 2, www.monetaecivilta.it

(58) F. Chaves Tristan, Tesoros en el Sur de Hispania. Conjuntos de denarios y objetos de plata durante los siglos II y I a.C., Sevilla, 1996, pp. 494-496, 547.

(59) Idea ya expuesta en por él en op. cit. en nota 56 y en la que insiste en Coinage and Money Under the Roman Republic, Cambridge 1985, p. 97. Por ello justifica, según su opinión y aunque años antes opinase de otra manera, el inicio del denario ibérico en esa fecha, pensando que con él Roma pagaría a sus tropas, teoría discutida y con abundante bibliografía que no podemos incluir en este espacio, pero véase al respecto M. A. AGUiLAR, T. ÑACO, "Fiscalidad romana y la aparición de la moneda ibérica. Apuntes para una discusión. I. Periodo interprovincial (206-195 a. C.)", Anejos AEspA XIV, 1995, pp. 281-288; A. BELTRÁN, "De nuevo sobre el origen y la función del denario ibérico" en La moneda en la societat ibèrica, II Curs d'Història Monetària d'Hispània, Barcelona 1998, pp. 101-117; M². P. GarCíA-BelLido, "Origen y función del denario ibérico", Sprachen und Insrifchtendes Antiken Mittelmeerraums. Festschrift für Jürgen Untermann zum 65. Geburtstag, Innsbruck 1993, pp. 97-123.

${ }^{(6) 1)}$ L. VILLARONGA, "La monnaie d'argent en Espagne de l'arrivée des romains jusqu'à la moitié du IIè siècle av. J. C.", Rythmes de la production monétaire de l'Antiquité à nos jours, Louvain-la-Neuve, 1987, pp. 99-117.
} 
campaña consiguieron solventar in situ (Liv. XXXIV, 9, 12; id. XL, 35, 4). Asimismo se ha dicho que la solución pasó por el uso de la ceca de la aliada Emporion, su gran suministradora de dracmas ${ }^{(61)}$ para los grandes gastos bélicos, y por los botines y multas o exacciones con que gravaban ${ }^{(62)}$ a los indígenas anti-romanos.

Pero es difícil admitir que en 12 años de guerra continuada y el consiguiente desplazamiento de numerosas legiones no hubiese necesitado mover consigo dinero romano en plata, más si tenemos en cuenta que la conquista, y por tanto el ejército, seguirían actuando continuamente en el suelo de Iberia. Por último, la propuesta de que Roma emitió ciertas monedas en Hispania como dobles y medios victoriatos etc. para cubrir los gastos de la guerra con los cartagineses ${ }^{(63)}$ se basa en tan escasísimos y a veces dudosos ejemplares, que su volumen de emisión no serviría más que para una mínima parcela de gastos o para solventar una situación muy puntual.

Más adelante, la reiterada y masiva presencia de las legiones durante las largas contiendas con celtíberos y lusitanos, en una época en que ya sí que cobraban en denarios los soldados, al menos aparentemente, deja una presencia más apreciable de monedas acuñadas por entonces que permanecen circulando en Hispania. Pero es sin duda el último cuarto del siglo II a. C. el que refleja una fuerte entrada de numerario argénteo emitido esos $\operatorname{años}^{(64)}$ y los inmediatamente anteriores. La densa concentración de tesoros con denarios producidos en la ceca de Roma en las zonas de ricos recursos, en especial de las minas de la cabecera del Baetis, nos han hecho pensar que esas monedas estaban viajando, de las costas itálicas a las hispanas, en las

\footnotetext{
(61) L. Villatonga, "Uso de la ceca de Emporion por los romanos para cubrir sus necesidades financieras en la Península Ibérica durante la II Guerra Púnica", Studi per Laura Breglia I, suppl. Boll. di Num. 4, 1987, pp. 219-214.

${ }^{(62)}$ T. ÑACO, "La presión fiscal romana durante las primeras décadas de la conquista de Hispania (218-171 a. C.): un modelo a debate", Studia Histórica 17, 1999, pp. 321-369, en especial 367 ss.; T. NACO, A. PRIETO cit. en nota 13, pp. 193-220, en especial 214 ss.

${ }^{(63)} \mathrm{M}^{\mathrm{a}}$. P. GARCía-Bellido, "La moneda hispánica en los horizontes bélicos peninsulares", E. Pérez González, E. Illarregui eds., Arqueología militar romana en Europa, Segovia 2005, pp. 31-33.

${ }^{(64)}$ F. CHAVES, op. cit. nota 58, pp. 547-560.
} 
bolsas de los negociantes ${ }^{(65)}$ y no exclusivamente de los soldados. En la actualidad estudiamos si un fenómeno similar pudo ocurrir en Lusitania desde el final del primer tercio del siglo I a. C. hasta los inicios del Imperio, donde se han hallado numerosos tesoros, siguiendo con esto la idea que ya expuso Alarcao $^{(66)}$. Ciertamente hubo movimiento de tropas en la zona lusitana -cosa que ya no era nueva- pero también se empezaban a explotar cada vez en mayor escala sus recursos económicos.

Si la plata viajaba en manos de aquellos que la utilizaban para agilizar sus negocios, la moneda fraccionaria cruzaba también las aguas del Mediterráneo aunque de forma aparentemente más reducida. La razón es que el bronce no mantiene un valor intrínseco tan evidente como la plata y, fuera de su zona de emisión era menos apreciado quedando como moneda "de bolsillo", útil tan sólo en pequeñas transacciones. Sin embargo es posible que esta visión, que reviste al bronce de un carácter secundario, no sea tan adecuada a la realidad. Es habitual fijar nuestra atención en los relativamente abundantes tesoros de metales preciosos sin pararnos a pensar que si ciertamente fue la moneda de plata la que se tesaurizó con más interés por el valor superior del metal contenido, debemos también advertir que los hallazgos esporádicos de bronces republicanos ${ }^{(67)}$, e incluso de algunos escondrijos ${ }^{(68)}$, nos muestran que esta moneda fraccionaria también atravesó el Mediterráneo con asiduidad.

\footnotetext{
(65) Ibid. y F.Chaves Tristán, P. Otero Morán, "Los hallazgos monetales", J. M. Blázquez, C. Domergue, P. Sillières, La mine et le village minière antique de La Loba (Fuenteobejuna, province de Cordoube, Espagne, Ausonius Mémoires 7, Bordeaux 2002, pp. 161-230.

(66) J. de AlarCÂO, "O contexto histórico dos tesouros republicanos romanos em Portugal", en R. M. S. Centeno, Ma . P. García-Bellido, G. Mora, eds., Rutas, ciudades y moneda en Hispania, Anejos AEspA XX, 1997, p. 3.

(67) Una recopilación no exhaustiva y correspondiente sólo a una zona de la Península Ibérica, pero que da una idea de su expansión en A. ARÉvalo, C. Marcos, El depósito monetal de Torelló d'en Cintes (Mabón, Menorca), Barcelona 1998, pp. 43-74.

(68) F. Chaves TRISTÁN: "Consideraciones sobre los tesorillos de monedas de bronce en Hispania. República e inicios del Imperio romano. II", Homenatge al Dr. Leandre Villaronga Acta Numismática 21-22-23 Barcelona, 1991-1992-1993, pp. 267-284.
} 
En el interior de la propia Península Ibérica la relación entre ciudades o zonas por motivos económicos aparece reflejada en el fenómeno monetario de forma bastante clara. Obsérvese el caso de las piezas de Obulco reacuñadas en $A_{c i n i p{ }^{(69)}}$, o las de Ilipa que se encuentran desplazadas hacia la zona de minas extremeña ${ }^{(70)}$, e incluso la reiterada presencia en Castulo de monedas emitidas en una alejada ceca de la Citerior, kese, contramarcadas y sin duda relacionadas con las minas ${ }^{(71)}$, tema que necesita un estudio detenido.

En cambio la moneda de bronce hispana viajó poco hacia Italia aunque conocemos casos interesantes como el de las piezas ebusitanas que se han encontrado en un número apreciable en Pompeya ${ }^{(72)}$, detectadas también recientemente en otras zonas de Campania donde incluso llegan a ser imitadas ${ }^{(73)}$. Pero sin duda los ejemplos más notables de las monedas de la Península Ibérica desplazadas a través del Mediterráneo son las monedas locales hispanas que han aparecido en el Norte de África ${ }^{(74)}$. La representación más abundante con mucha diferencia pertenece a Gadir, seguida de Carteia y Malaca aunque se detecta la presencia minoritaria de varias cecas más. La reiterada aparición de estas piezas frente a la menor -aunque también existente- de las africanas en las costas de Iberia ${ }^{(75)}$ - nos plantea una

${ }^{(69)}$ B. Mora, "Reacuñaciones de la ceca de Acinipo", Acta Numismática 17-18, 1987-88, pp. 89-100 .

(70) A. ARÉVAlo, "La dispersión de las monedas de Ilipa Magna", IX CNN, Elche 1994, pp. 39-48.

${ }^{(71)} M^{a}$. P. GarCía-Bellido, "Nuevos documentos sobre minería y agricultura en Hispania", AEspA 153-154, 1986, pp. $13-46$.

(72) A. STAZIO, "Rapporti tra Pompei ed Ebusus nelle Baleari alla luce dei rinvenimenti monetali", AIIN 2, 1955, pp. 33-57.

${ }^{(73)} \mathrm{C}$. STANNARD, "Numismatic evidence for relations between Spain and central Italy at the turn of the first and second centuryes B. C.", XIII CIN, Madrid, 2005.

(74) E. Gozalbes Cravioto, Economía de la Mauritania Tingitana (s I a. C- II d. C), Ceuta 1997, pp. 141-159; ibid. "Vías de comunicación entre Hispania y el norte de África en época romana" Arqueología da Antiguidade na Peninsula Iberica, III Congr. Arq. Peninsular, Oporto 2000, pp. 253-265; L. Callegarin, F. Zohra El Harrif, "Ateliers et échanges monétaires dans le Circuit du Detroit" en $\mathrm{M}^{a}$. P. García-Bellido, L. Callegarin eds, Los cartagineses y la monetización del Mediterräneo occidental, Anejos AEspA XXII, pp. 23-42.

(75) Ibid.; E. Gozalbes Cravioto, "Un documento del comercio hispano-Africano: las monedas de cecas mauritanas aparecidas en Hispania", Homenaje al Prof. Carlos Posac Mon, Instituto de Estudios Ceuties 1998, I, pp. 207-227; F. Chaves, E. GarCía, E. Ferrer, "Datos relativos a la 
interrogante que por el momento es complicado solventar. ¿Viajaron estas monedas para desempeñar una función económica ligada al comercio entre ambas orillas del Estrecho, emitidas en una lengua común y siguiendo patrones similares en una zona donde la única plata sería en todo caso el denario romano, moneda "extranjera"? Al menos en la zona africana, no perteneciente aún a Roma, la moneda romana podría considerarse como foránea ¿Son por el contrario simple testimonio de la gran frecuencia de desplazamientos de las poblaciones de un lado a otro del Estrecho, y se limitan a ser meras pérdidas ocasionales?

Es más lógica la primera propuesta si pensamos que los hallazgos de moneda hispana son más frecuentes en el Norte de África donde se cotizarían a pesar de ser bronce ya que Mauritania también iba a acuñar moneda en este metal aunque el inicio de las emisiones mauras es sin duda posterior al conjunto de las hispanas ${ }^{(76)}$. El uso de pequeños bronces, asociado en el Estrecho a las industrias relacionadas con pesca, salazones y salsas de pescado se atestigua por los hallazgos que cada vez se amplían más ${ }^{77}$. Estas

pervivencia del denominado Circulo del Estrecho en época republicana", África Romana XII, Sassari 1998, pp. 1307-1320; ibid. "Sertorio: de África a Hispania", África Romana XIII, 2000, pp. 1463-1486; B. MORA. "La circulación monetaria en los territorios malacitanos durante la Antigüedad" en Comercio y comerciantes en la Historia Antigua de Málaga (S. VIII a.C-711 d.C), F. Wulff, G. Cruz Andreotti, C. Martinez Maza eds., Málaga 2001, pp. 419-455.

(76) La cronología de las series más antiguas de esta zona está en revisión. Tradicionalmente se venían situando hacia mediados del siglo I a. C. pero en época reciente se advierte una tendencia a subir la cronología al menos de ciertas emisiones. Es el caso de algunas series atribuídas a Bocco II (49-33 a. C.) que ahora se llevan a Bocco I (118-81 a. C) por diversas razones: L. CAllegarin, F. ZOHRA El HarRif, cit. en nota 74, p. 31-34. Análisis metalográficos realizados sobre estas monedas y otras de cecas locales que se vienen considerando también tardías, presentan una semejanza en su composición metálica que induce a reflexionar sobre su coetaneidad: $\mathrm{F}$. Chaves tristán, R. Pliego, B. Gómez-Tubío, M. A. Respaldiza: "Análisis metalográficos de monedas procedentes de cecas púnicas del sur de la Península Ibérica y del norte de Africa", In Memoriam Tony Hackens, Revue Belge de Numismatique, CXLV, 1999, pp. 199-214. Por otra parte, Callegarin y El Harrif (cit. p. 37-38), reflexionando no sólo acerca de las monedas hispanas halladas en excavaciones - Thamusida y Zilil- sino también teniendo en cuenta el material cerámico, concluyen que la época de Bocco I muestra una apertura a los movimientos comerciales del Mediterráneo lo que, en nuestra opinión, la presenta como un momento favorable para el inicio de algunas amonedaciones.

(77) C. Alfaro, Las monedas de Gadir/Gades, Madrid 1988; ibid, "Observaciones sobre producción y circulación del numerario de Gadir", IV Congr. Int. Estudios Fenicios y Púnicos, Cádiz, 2000, pp. 427-432; A: ARÉVAlo, "Sobre la presencia de moneda en los talleres alfareros de San Fernando 
piezas debieron compensar de alguna manera el trabajo en dichas labores y es muy posible que cierta mano de obra norte africana atravesase el Estrecho hasta la costa hispana para trabajar como temporeros portando a su vuelta las ganancias adquiridas. De hecho las monedas en cuestión no penetran apenas en el interior mauritano(78).

La moneda, viajera en los bolsillos de gentes que se desplazaron buscando un trabajo, cuenta con otro buen ejemplo en las minas de la Bética. Aunque este caso no conlleve atravesar el mar, el movimiento de personas que desde la Citerior descendían a trabajar e las minas del $\operatorname{sur}^{(79)}$ se muestra con toda claridad en el poblado minero de La Loba. Al igual que en otros yacimientos de condiciones similares se observa a través de las monedas aparecidas cómo gentes de la Celtiberia bajaban a los poblados de la cuenca minera del Guadalquivir portando consigo algunos bronces, emitidos en cecas de su tierra. Incluso en alguna ocasión las monedas nos han llegado formando un pequeño ahorro con piezas procedentes de la celtíbera Arekorata $^{(80)}$.

Queda aún un tema que pudo producir el desplazamiento de monedas tanto por mar como por tierra: las visitas a los santuarios y lugares de culto ${ }^{(81)}$. En forma de ofrenda los fieles depositaban piezas monetales traídas desde sus puntos de origen como se muestra en las recogidas en Vicarello, Rio Liri, etc. Una somera revisión de estos lugares en la Península Ibérica ${ }^{(82)}$ parece

(Cádiz)", en D. Bernal, L. Lagóstena, eds. Figlinae Baeticae. Talleres alfareros y producciones cerámicas en la Bética romana (ss. II a. C.-VII d. C.), BAR int. Ser. 1266, 2004, pp. 515-516.

${ }^{(78)}$ El movimiento de personas por trabajo temporal también lo sugiere, siguiendo a M. Ponsich, E. Gozalbes CRAvioto, "Notas sobre las relaciones hispano-tingitanas en la Antigüedad clásica", en Vivre, produire et échanger: reflets méditerranéens, Mélanges offerts à Bernard Liou, Montagnac 2002, p. 138.

(79) P. OTERO, "Consideraciones sobre la presencia de acuñaciones celtibéricas en zonas mineras de la Hispania Ulterior", XI CIN, Louvain-la-Neuve 1993, pp. 49-58.

${ }^{(80)}$ F. Chaves, P. OTERO, op.cit. nota 65, pp. 174-177, 214-215.

${ }^{(81)}$ Los casos en el Mediterráneo podrían ser bastantes. Citemos como ejemplo las monedas púnicas halladas en el santuario etrusco la Punta della Vipera (Santa Marinella), citado por A. DOMINGUEZ ARRANZ, "La Castellana del Marangone (cerca de Civitavecchia, Italia): hallazgos monetarios", XIII CIN, Madrid 2005, pp. 555 y nota 26.

${ }^{(82)}$ A. ARÉvalo, C. MarCos, "Sobre la presencia de moneda en los santuarios hispánicos", XII CIN Berlin, 2000, pp. 28-38. 
mostrar, salvo excepciones ${ }^{(83)}$, una circulación local. Pero la presencia de denarios romanos y en especial la abundancia de bronces republicanos, nos suscita la duda de si formaban simplemente parte del circulante de la zona o habían sido depositados por personas que los trajeron consigo en su viaje desde Italia. En este sentido no está de más recordar que en el arriba mencionado poblado minero de La Loba, se halló una hilera de 14 denarios depositados a lo largo de las piedras de un muro, en una casa que parece haber sido habitada por gentes procedentes de Italia, dedicados a modo de ofrenda para conseguir prosperidad y buena fortuna ${ }^{(84)}$.

Este breve abanico de posibilidades que hemos esbozado pretende observar mediante ejemplos concretos cómo las monedas atravesaron el Mare Nostrum con fluidez y frecuencia. Las razones del movimiento de sus portadores fueron variadas y a veces complejas de descifrar: un minucioso estudio de viajes, presencias y ausencias nos aportará sin duda una visión más clara de la sociedad de cada época.

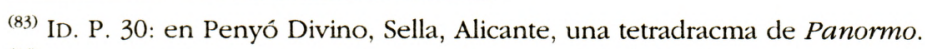

${ }^{(84)}$ F. Chaves, P. OTERO, op. cit. nota 65, pp. 172-174, 211-214. 